\title{
VEINTICINCO AÑOS DE ESTADO AUTONÓMICO: UNA MALA SOLUCIÓN ORGANIZATIVA PARA UN PROBLEMA POLÍTICO
}

\author{
ÁLVARO XOSÉ LÓPEZ MIRA \\ ProfesorTitular de Ciencia Política \\ Univerșidad de Vigo
}




\section{SUMARIO}

1. RETAZOS histórICOS. 2. El MOdELO DE ORGANIZACIÓNTERRITORIAL EN LA CONStitución de 1978. 3. El statu quo politico. 4. Algunas conclusiones. 


\title{
VEINTICINCO AÑOS DE ESTADO AUTONÓMICO: UNA MALA SOLUCIÓN ORGANIZATIVA PARA UN PROBLEMA POLÍTICO
}

\author{
POR \\ ÁLVARO XOSÉ LÓPEZ MIRA \\ ProfesorTitular de Ciencia Política \\ Universidad de Vigo
}

\section{RETAZOS HISTÓRICOS}

Pese a ser considerado tradicionalmente uno de los Estadosnación más antiguos de Europa, todavía durante la primera mitad del siglo XIX en España no existía "un Estado propiamente dicho, sino un pais políticamente desarticulado" " , incluso hasta 1931 se podría llegar a afirmar que, "utilizando criterios muy estrictos, apenas hubo Estado ${ }^{2}$. llustrativo resulta señalar como todavía en 1874 , veinte ciudades españolas tenían bancos que emitían su propia moneda, hasta que en ese año el Gobierno le concedió el monopolio de la emisión al Banco

1 Antonio ToRres del Moral: Constitucionalismo histórico español, Madrid, Átomo, 1988, 2. ${ }^{a}$ ed., pág. 17.

2 lbid., pág. 25. 
de España. La soberanía y sus símbolos ${ }^{3}$, el propio Estado en el sentido fuerte de la expresión, fueron epidérmicos en bastantes aspectos hasta la consolidación de la dictadura franquista.

De todas formas, existe una cierta constante histórica tendente a la centralización del poder político en detrimento de los antiguos Reinos que formaban la Monarquía española, sobre todo tras la implantación de la dinastía borbónica en el siglo XVIII y, posteriormente, por parte de los liberales españoles que importaron las ideas de la Francia revolucionaria. Con todo, la reivindicación bajo modernas formulaciones nacionalistas del País Vasco, Cataluña y Galicia, no comenzaran a forjarse hasta el último tercio del siglo XIX, justo cuando el manto del unitarismo estatal va cobrando, de modo paulatino, mayor fortaleza.

Los doctrinarios españoles, más progresistas o más moderados ideológicamente, coinciden en catalogar dichas reivindicaciones como retrógradas, más ancladas en el Antiguo Régimen que en las nuevas ideas de modernidad y progreso. Por consiguiente, los nacionalismos vasco y catalán y, en menor medida por su escaso vigor, el gallego, pasan a ser considerados como un problema más de los aquejan a España (junto al atraso económico y la desintegración social) y, por lo tanto, necesitado de una solución más o menos drástica; la carga peyorativa de la expresión problema no deja lugar a dudas.

Dando un salto en el tiempo, en aras de la brevedad, conviene indicar cómo políticamente, tres cuartas partes del siglo $X X$ español son una larga dictadura salpicada por la breve mancha democrática que supuso la Segunda República (1931-1936), por lo cual los nacionalismos catalán, vasco y gallego sobreviven sólo larvadamente ante la virulencia del nacionalismo español que impuso la autocracia franquista. De manera sorprendente, a pesar de la absoluta manipulación propagandística de los medios de comunicación de masas empleada por casi cuarenta años de prolongada dictadura (una única cultura, una sola lengua, la de Castilla, un único aparato político-administrativo radicado en la capital del Estado, etc.), las primeras elecciones democráticas celebradas en 1977 desvelan el notable apoyo que tienen los nacionalismos vasco y catalán (bastante menor el gallego) en sus respectivos territorios y sociedades civiles, obteniendo grupos parla-

3 Incluido el himno nacional (carente de letra), cuyos acordes tributaban estipendios del erario público cada vez que sonaban a los herederos de su autor hasta 1997. 
mentarios propios en las dos Cámaras legislativas recién creadas: Congreso de los diputados y Senado. Una vez más, la recurrente terquedad del fenómeno se repetía, por lo que a las fuerzas políticas de ámbito estatal ${ }^{4}$ no les quedó más alternativa que negociar un texto constitucional que pudiese ser aceptado por los nacionalismos periféricos para integrarlos en la singladura democrática que entonces se iniciaba.

\section{EL MODELO DE ORGANIZACIÓNTERRITORIAL EN LA CONSTITUCIÓN DE 1978}

Fruto de un consenso relativamente amplio ${ }^{5}$, el extenso Título VIII de la vigente Constitución, regulador de la organización territorial del Estado, resulta notoriamente indefinido e incluso, en algunos aspectos, bastante confuso. Hasta en los matices léxicos, la ambigüedad es nota predominante en la determinación del nuevo nivel territorial descentralizador del anterior modelo de Estado unitario- que se quiere implantar: nacionalidades, regiones, Comunidades Autónomas son denominaciones que generan una imprecisión conceptual completamente inapropiada en términos jurídicos. No obstante, en nuestra opinión, una gran virtud política atempera los obvios defectos jurídicos, en concreto, el intento de buscar una solución racional que procurase - desde una perspectiva posibilista - aliviar los conflictos centro-periferia característicos de la historia española e intentar armonizar la convivencia entre los diversos pueblos que componen el mosaico peninsular.

La mutua desconfianza e incluso las amenazas de involución por parte de los aún poderosos militares hacia la todavía inestable democracia española, provocaron que las reivindicaciones de los nacionalistas periféricos quedasen reconducidas a márgenes bastante estrechos, en el sentido expresado por el profesor Xacobe Bastida: «La existencia de nacionalidades está supeditada a su ausencia de pulsión

4 Las dos más importantes en este momento eran UCD (Unión de Centro Democrático y PSOE (Partido Socialista Obrero Español) que alcanzaron, respectivamente, 165 y 118 escaños de los 350 que componían la Cámara Baja.

5 De entre los grupos mayoritarios, los nacionalistas moderados vascos fueron los únicos que no lo suscribieron, pero tampoco lo negaron. Optaron por la abstención.

6 Xacobe BASTIDA: La nación española y el nacionalismo constitucional, Barcelona, Ariel, 1998, pág. 85. 
soberana; su vigencia es posible en tanto en cuanto no impugnen el prius de la unidad de la nación española” ${ }^{6}$, dejando reducido el término nacionalidad a un mero sinónimo de especificidad cultural dentro de una única nación política, la española.

Rechazada la posibilidad de instaurar un modelo federal al identificar, incomprensiblemente, la élite política española federalismo con separatismo, se optó por una vía de descentralización de competencias estatales, otorgándole ciertos poderes políticos a la entidad territorial de nueva creación, la Comunidad Autónoma. Pensado inicialmente para los casos catalán, vasco y gallego, se extendió con posterioridad a la totalidad del territorio estatal 7 , con la finalidad política de limitar las pretensiones de las nacionalidades históricas, intentando reducirlas al papel de naciones culturales, creándoles, aparentemente, artificiosos competidores.

La señalada ambigüedad delTítulo VIII de la Constitución facilitó, en algunos aspectos, la negociación política entre las partes pero, simultáneamente, provocó que, tras veinte años de vigencia del modelo, se produjese una recentralización del mismo, especialmente a través de la interpretación del Tribunal Constitucional en los numerosos conflictos de competencias propiciados por la indefinición de la Carta Magna; este organismo colmó las lagunas existentes en ella casi siempre en sentido contrario a las pretensiones autonómicas ${ }^{8}$, cuando podría haber sido de otra forma. En resumen, la situación actual al respecto se puede compendiar en los siguientes puntos:

a) El mencionado papel del Tribunal Constitucional y la escasa sensibilidad autonomista mostrada por los partidos de ámbito estatal, quizás en parte fomentada por el movimiento terrorista vasco y su importante apoyo social, o acaso por una atávica creencia, todavía arraigada, de que resulta posible homogeneizar España.

b) Un Senado (Cámara Alta del poder legislativo) que no desempeña en absoluto su rol constitucional de Cámara de representación territorial ${ }^{9}$, ya que los senadores de desig-

7 Creando algunas Comunidades Autónomas absurdas, sin el menor arraigo histórico o social, como la de Madrid, entre otras.

8 Habría que indicar cómo todos los magistrados del Alto Tribunal son designados por órganos centrales del Estado y ninguno por parte de las Comunidades Autónomas, contrariamente al Tribunal Constitucional Federal alemán.

9 Existe práctica unanimidad doctrinal respecto de esta afirmación. 
nación autonómica son una pequeña parte de la cifra total y el peso de esta Cámara es totalmente secundario en relación con el Congreso de los diputados, que es donde los partidos nacionalistas prefieren obtener representantes.

c) Una prácticamente nula competencia autonómica en materias relativas al poder judicial; y muy disminuidas en otros temas por la recurrrente apelación de los poderes centrales a la cláusula jurídica indeterminada del interés general, el cual es interpretado libremente sobre todo por la instancia gubernamental y sus apoyos partidarios en el legislativo; así, sólo por citar algunos ejemplos, la autoorganización interna del régimen local por parte de las Comunidades Autónomas, los impedimentos a la intervención directa en el ámbito de la Unión Europea en asuntos de exclusiva competencia autonómica, etc., etc.

d) El espinoso tema de la financiación autonómica es cuestión sin resolver de manera definitiva ${ }^{10}$, objeto de negociaciones anuales, alejada todavía de criterios de federalismo fiscal $y$, lo que es más importante, la inestabilidad y dependencia financiera de las Comunidades Autónomas que esta situación provoca las incapacita también, en buena medida, para ejercer realmente su autonomía política.

Muchas otras consideraciones podrían ser resaltadas al hilo de este discurso, como los temores existentes a las necesarias reformas constitucionales tras casi veinticinco años de vigencia o la imposibilidad para las Comunidades Autónomas de reformar sus Estatutos de Autonomía sin la intervención y aquiescencia de los poderes centrales; pero, tal vez, lo que interesa destacar aquí es que se comienza a percibir un cierto agotamiento del modelo diseñado en 1978. Ha resultado útil para descentralizar el poder $y$, por lo tanto, ha supuesto un cambio importante en la tradición centralista del Estado español, pero se ha mostrado incapaz como solución organizativa de responder a las demandas por causa de las cuales en realidad fue creado: la percepción de determinados territorios de su diferencialismo lingüistico"11,

10 Habría que indicar que es diferente en los históricos supuestos vasco y navarro, cuyos mecanismos fiscales ya son anteriores a la actual Constitución.

11 El catalán es entendido por el $94 \%$ de la población y hablado por el $68 \%$ dentro de su ámbito territorial, aunque también es hablado en las Comunidades Autónomas de las Islas Baleares y Valenciana. En Galicia el gallego es entendido por la práctica totalidad de la población y hablado por casi el $80 \%$ de la misma. El 
cultural, histórico, etc., el cual desean que se vea traducido también en un diferencialismo politico que salvaguarde su identidad; obviamente la gradación en el mismo es variable: desde el regionalismo al federalismo o la autodeterminación existen numerosos escalones intermedios, y no es exactamente igual la reivindicación de los nacionalistas de izquierda vascos y catalanes que la de los nacionalistas de centro, mayoritarios en sus respectivas Comunidades Autónomas. Lo que sí parece cierto es que la complejidad del fenómeno ya no es abordable desde la actual visión político-constitucional. Que en el seno de la avanzada Europa unida de los albores del siglo XXI exista un movimiento terrorista tan virulento y arraigado socialmente al que se está respondiendo con un reverdecido nacionalismo español hace percibir la necesidad de no pensar en soluciones fáciles.

\section{EL STATU QUO POLITICO}

El aludido fenómeno terrorista no debe ocultar el hecho de que los nacionalismos periféricos existentes en España son mayoritariamente democráticos, en la línea de recuperación de identidades nacionales de pequeños territorios observables en lugares tan dispares como Quebec, Escocia o Flandes ${ }^{12}$. Y los dilemas suscitados son parecidos en todas partes; ¿deben estas naciones crear su propio Estado en un compás histórico en que la noción de soberanía está perdiendo aceleradamente entidad? Si mayorías democráticas así lo solicitan, ¿cómo no incurrir en contradicciones en Estados que, justamente, defienden la democracia y sus métodos?; bastaria pensar en el ejemplo eslovaco. ¿Pueden existir soluciones intermedias como ha acontecido en los clásicos modelos federales alemán, estadounidense o helvético?

En el caso español, en Cataluña la fuerza política más importante es la coalición CiU (Convergència i Unió). Su líder, Jordi Pujol, ha vencido en los seis comicios autonómicos celebrados desde 1980, aunque sin mayoría absoluta en los dos últimos. El segundo partido en Cataluña es el PSC-PSOE (Partido Socialista Catalán), el cual merece citarse porque, aunque no es en puridad nacionalista, si que defiende un modelo de Estado federalista y el diferencialismo cultural, económico y político de Cataluña, contrariamente a la mayor par-

12 Vid. Michael Keating: Nations against the State. The New Politics of Nationalism in Quebec, Catalonia and Scotland, London, Macmillan, 1996. 
te del resto de los socialistas españoles. La izquierda nacionalista independentista que representa ERC (Esquerra Republicana de Catalunya) se encuentra a gran distancia en peso electoral de los dos partidos citados.

El panorama de partidos nacionalistas vascos es más complejo. En la actualidad el más importante es el histórico PNV (Partido Nacionalista Vasco), de talante conservador y demócrata-cristiano pero con un nacionalismo más exacerbado que el de CiU. Esta fuerza política ha sido la más votada en todas las elecciones autonómicas desde 1980 y siempre ha dirigido el Gobierno vasco, pero habitualmente necesitando otros apoyos parlamentarios al no alcanzar mayorías absolutas, puesto que existe una gran fragmentación. El segundo partido nacionalista en votos y escaños era, hasta su reciente y polémica ilegalización, la coalición EH (Euskal Herritarrok), quinto en el conjunto vasco tras el PSOE (Partido Socialista Obrero Español) y tras el PP (Partido Popular) después de las últimas elecciones autonómicas de 2001; defiende la independencia del País Vasco y apoya, bastante explícitamente, al grupo armado ETA ${ }^{13}$ y su entorno; aunque se presentaba a las elecciones, normalmente no acudía a las convocatorias de los foros democráticos donde obtenía representación (Parlamento Vasco o Cortes Generales españolas). La tercera fuerza nacionalista es EA (Eusko Alkartasuna), sexta en el conjunto de partidos vascos, fruto de una excisión del PNV, socialdemócrata, se encuentra a notable distancia en votos y escaños de las anteriores aunque, en la actualidad, forma coalición en el Gobierno vasco y, cada día más, ha forjado una alianza electoral estable con el PNV.

En Galicia el nacionalismo siempre ha tenido una mayor influencia cultural que política. Sin embargo, en el momento presente, la segunda fuerza en el Parlamento autonómico es la coalición electoral nacionalista de izquierdas BNG (Bloque Nacionalista Galego), aunque se encuentra muy distante de la fuerza mayoritaria en Galicia en los últimos trece años, el Partido Popular que, en esta nacionalidad, se reviste de unos tintes de culturalismo galleguista, que no se estilan en otras regiones entre los populares.

Refiriéndonos a los resultados electorales en el conjunto español para la Cámara predominante (el Congreso de los diputados), hay que indicar que los dos partidos más importantes de ámbito estatal

13 Por ejemplo, mediante la inclusión en sus listas electorales de miembros de dicha organización terrorista. 
(UCD ${ }^{14}$ y PSOE en 1977 y 1979; PP y PSOE desde entonces), siempre han logrado una cifra que rondaba los trescientos escaños de los trescientos cincuenta que configuran la Cámara baja del Parlamento español. De las ocho convocatorias electorales celebradas desde 1977, el PSOE alcanzó mayoría absoluta en 1982, 1986 y 1989, y el PP en las últimas, las celebradas en el año 2000. En las cuatro restantes, los partidos de ámbito estatal que formaron Gobierno por resultar los más votados (UCD en 1977 y 1979, el PSOE en 1993 y el PP en 1996), precisaron de apoyos parlamentarios para poder hacerlo, consiguiéndolos en todos los casos gracias a los nacionalistas catalanes de $\mathrm{CiU}$ y, en menor medida, a los vascos del PNV15.

Dicha configuración del espectro político viene, en parte, propiciada por un sistema electoral que, definiéndose como proporcional, tiene tendencias claramente mayoritarias, beneficiando al partido o dos partidos más votados a nivel estatal, pero sin perjudicar a los partidos que concentran sus sufragios en unas pocas circunscripciones, como sucede con $\mathrm{CiU}$ y el PNV quienes en todas las legislaturas obtuvieron grupos parlamentarios propios en el Congreso ${ }^{16}$. El apoyo social sostenido a lo largo de los años y su traducción en votos hace apreciar la circunstancia de que los nacionalismos periféricos españoles no son un fenómeno coyuntural como, a veces, cabria inferir de una lectura superficial de los mass media españoles respecto de este fenómeno.

La necesidad que los distintos partidos de ámbito nacional tuvieron de pactar con ellos, no ha impedido que estos mismos partidos los satanizaran cuando ya no la tenían, sobre todo en campañas electorales. Y si bien es cierto que gracias a su apoyo parlamentario obtuvieron a cambio algunos beneficios para sus respectivas Comunidades, cuestión de puro sentido común en cualquier pacto político, no lo es menos que el referido intento de acusarlos de egoístas, mentirosos y malvados ${ }^{17}$ ha servido - todavía sirve - de baza política a algu-

14 Unión de Centro Democrático, partido ya desaparecido.

15 Hemos excluido de este análisis otros grupos nacionalistas de otras Comunidades Autónomas bien por carecer de relevancia electoral dentro de su ámbito territorial y, mucho menos, a nivel del Estado, bien por no encajar dentro de una definición científica estricta de nacionalismo, pudiendo ser mejor catalogados como regionalistas.

16 Paradójicamente, los nacionalistas gallegos del BNG se han visto hasta la fecha notablemente infrarrepresentados en las circunscripciones de Galicia.

17 A los moderadísimos nacionalistas catalanes se les ha llegado a comparar con los brutales agresores serbios de Bosnia, por poner un único ejemplo. 
no de los grandes partidos estatales (PP o PSOE) para captar votos en otras partes de España cuando ya no los precisaban, lo que es un claro rasgo de inmadurez e irresponsabilidad política, sobre todo si tenemos en cuenta el hecho de que los posibles desacuerdos con los nacionalistas en materia de modelo de Estado, aún no ha llegado a propiciar una gran coalición entre los dos partidos mayoritarios, dominantes con gran holgura en el Parlamento ${ }^{18}$.

\section{ALGUNAS CONCLUSIONES}

En realidad tendriamos que remontarnos a reflexiones anteriores para volver a señalar cómo el vigente modelo autonómico no parece, en la actualidad, satisfacer a aquellas nacionalidades diferenciadas para las que fue originariamente creado. Consecuentemente, su validez en términos absolutos tiene que ser puesta en entredicho, aunque se pueda mantener para las restantes regiones españolas. En todo caso, opinamos, que no cabría calificarlo como un fracaso, sino como un paso histórico en el camino de la descentralización.

Una solución auténticamente federal, con reconocimiento de la plurinacionalidad del Estado, una Cámara de representación territorial con potestades de esta indole, un Tribunal Constitucional de designación equitativa entre las nacionalidades y los órganos centrales, unas Constituciones de los Estados miembros que ellos mismos pudieran reformar respetando las directrices de la Constitución federal, federalismo fiscal, federalización del poder judicial y una cierta intervención en los asuntos europeos que les afectasen, son elementos que parecen tan alejados de las intenciones de las fuerzas políticas mayoritarias de ámbito estatal como en 1978. Presumiblemente, este pacto federal sería aceptado por las fuerzas políticas mayoritarias en las tres nacionalidades históricas ${ }^{19}$. Más complicado resulta augurar la postura que adoptaría el nacionalismo radical vasco, especialmente en lo tocante al abandono de la violencia, aunque es probable que la base social que lo sustenta disminuyese de forma notable. Habría que men-

18 En la actualidad los cinco partidos nacionalistas de las tres nacionalidades cuentan con un total de 27 diputados en el Congreso (de un total de 350), 15 de ellos de CiU. Los grupos parlamentarios popular y socialista suman 308 escaños.

19 Recientemente, CiU, PNV y BNG han firmado una serie de acuerdos de colaboración política (Declaración de Barcelona) a favor de una solución de esta índole. 
cionar la ambigüedad calculada como arte política capaz de sacar provecho en condiciones de inferioridad, que siempre han utilizado los nacionalistas periféricos en cuanto a sus verdaderas pretensiones, así como señalar también que estos nacionalismos, unos más que otros, tienen dificultades para salir de sus iniciáticos marcos ideológicos y teóricos, aunque están demostrando cierta flexibilidad y capacidad de adaptación a los nuevos tiempos de globalización, asimismo, unos más que otros.

Cabría inferir, en consecuencia, que el modelo autonómico español podria ser exportado a otros países, de tradición centralista napoleónica, que pretendan descentralizar el poder político, como por ejemplo sucede en lberoamérica donde el federalismo es papel mojado en numerosas Constituciones, pero que sean más homogéneos culturalmente que la propia España. En caso contrario, seguramente el federalismo ofrezca mejores alternativas.

Parece, pues, en definitiva, que la organización territorial autonómica se ha erigido como un armazón, un corsé demasiado estrecho para que ese documento político que es la Constitución sirva de marco válido para todos en las reglas del juego democrático. Y lo cierto es que la historia política española está toda ella atravesada por un numeroso conjunto de Constituciones semánticas, en el sentido de Loewenstein, como para creer en mágicos efectos taumatúrgicos de la vigente al margen de la realidad, de la evolución de la conciencia social y política. 